\title{
EFFECTS OF SILVER NANOPARTICLES ON THYROID GLAND STRUCTURE AND FUNCTION IN FEMALE RATS
}

\author{
AMAL A SULAIMAN ${ }^{*}$, NOORI M LUAIBI ${ }^{2}$, HIBA A QASSIM $^{3}$ \\ ${ }^{1}$ Department of Pharmacology and Therapeutics, Baghdad College for Medical Sciences, Baghdad, Iraq. ${ }^{2}$ Department of Biology, College of \\ Science, Mustansiriyah University, Baghdad, Iraq. ${ }^{3}$ Al-KhabeerPrivate Laboratories for Clinical Analysis, Baghdad, Iraq. \\ Email: amal3_ajaweed@yahoo.com \\ Received: 29 August 2018, Revised and Accepted: 17 October 2018
}

ABSTRACT

Objective: Due to their unique properties, silver nanoparticles (AgNPs) gained a broad utilization in nano-based industries and medicine, which may expose human to increased levels of NPs. However, little is known about their potential harmful effects on endocrine physiology. Hence, this study aimed to investigate the potential dose- and time-dependent outcomes of AgNPs on serum levels of thyroid hormones and thyroid gland histology in female rats.

Methods: A total of 60 female rats were divided into three groups (each of 20 animals), treated with AgNPs for (10, 20, and 30) days. Within each treatment period, animals were assigned into four subgroups each of five rats; control treated with vehicle and the others treated with 12.5 , 25 , and $50 \mathrm{mg} / \mathrm{kg}$ of AgNPs, respectively, by intraperitoneal injection. At the end of treatments, all rats were sacrificed; blood samples were obtained and analyzed for serum levels of triiodothyronine (T3), thyroxine (T4) and thyroid stimulating hormone (TSH). Thyroid gland was removed and weighed then kept in buffered formalin solution for microscopic examination.

Results: The data showed a significant increase in the weight of the thyroid gland after 20 and 30 days of the treatment with 50 mg/kg of AgNPs, while the $25 \mathrm{mg} / \mathrm{kg}$ dose of AgNps resulted in significant increase only after 30 days. Serum levels of $\mathrm{T}_{3}$ and TSH were nonsignificantly altered by AgNPs in all the treatment groups. Thyroxin levels $\left(\mathrm{T}_{4}\right)$ were significantly decreased after long-term exposure. Histological specimens of AgNPs treated group showed disturbance of the normal architecture of the thyroid tissue with degeneration of thyroid follicles and desquamated luminal cells.

Conclusion: The results of the current study suggested the possible time and dose dependent disrupting potential of AgNPs on thyroid gland function and histology in female rats.

Keywords: Silver nanoparticles, Thyroid gland, Thyroxine, Thyroid-stimulating hormone.

(C) 2018 The Authors. Published by Innovare Academic Sciences Pvt Ltd. This is an open access article under the CC BY license (http://creativecommons. org/licenses/by/4. 0/) DOI: http://dx.doi.org/10.22159/ajpcr.2018.v11i11.29383

\section{INTRODUCTION}

During the past decades, the field of nanotechnology was rapidly expanded, and metal nanoparticles (NPs) displayed wide applications in the industrial and medicinal fields. Accordingly, the increased human exposure to NPs may represent a threat to the human health. Due to their antimicrobial activity, the silver NPs (AgNPs) are the most widely used NPs in the nano-based products [1]. Previous data have shown that exposure to AgNPs resulted in a variety of toxicological effects. Although to date insufficient studies are available about the potential systemic toxicity of the AgNPs, they suggested that the nature of nanotoxicity is dose-dependent and explored their potential cytotoxicity explored at high concentrations [2]. On the other hand, the low concentration of AgNPs may be involved in the alteration of cellular signaling pathways $[3,4]$. The small particle size of AgNPs enables them to cross biomembranes and localize at any site within the target organs including the liver, spleen, lung, kidney, thyroid, brain, and gonads inducing toxicity $[5,6]$. The thyroid gland plays an important role in the regulation of several physiological functions such as metabolic processes, neuronal growth, bone remodeling, and cardiac functions $[7,8]$. Accordingly, changes in the levels of thyroid hormones levels may significantly affect human health. However, many studies have clarified the possible contribution of NPs in such changes. The endocrine system is highly sensitive to the environmental pollutants, and it has been reported that about $10 \%$ of the population suffer from thyroid gland disorders, which may be considered as a major public health problem. Therefore, previous data have focused on the possible negative impact of environmental NPs as endocrine disrupting materials [9]. Although, the mechanisms by which AgNPs induce toxicity are not well recognized. It has been suggested that free oxygen radical production may explain the toxicity of AgNPs, as they can induce a wide range of physiological and cellular effects such as inflammation, DNA damage, and apoptosis $[10,11]$. The endocrine system is highly sensitive to the environmental pollutants, and it has been reported that about $10 \%$ of population suffer from thyroid gland disorders, which may be considered as a major public health problem [9]. Therefore, the present study was designed to investigate the impact of exposure time and concentration of AgNPs on thyroid gland structure and function of female rats.

\section{METHODS}

Preparation of AgNPs solution

AgNPs powder (Skyspring Nanomaterials, Houston, USA) of $99.95 \%$ purity was used in the present study. The particles have a spherical shape (20-30 nm) with a specific surface area of $20 \mathrm{~m}^{2} / \mathrm{g}$ and $10.5 \mathrm{~g} / \mathrm{cm}^{3}$ density. AgNPs stock suspension ( $40 \mathrm{mg} / \mathrm{ml}$ ) was freshly prepared by dispersing the weighed amount of AgNPs in deionized water and mixed by vortex for $10 \mathrm{~min}$. From this stock suspension, two additional diluted AgNPs suspensions (10 and $20 \mathrm{mg} / \mathrm{ml}$ ) were prepared. From theses diluted suspensions, the required dose volumes were calculated and injected intraperitoneally to the rats.

Animals

A total of 60 female Sprague-Dawley rats (225-250 g) were purchased from the National Center for Drug Control and Research/Ministry 
of Health, Baghdad, Iraq. All animals were maintained at controlled laboratory conditions of temperature $\left(25 \pm 2^{\circ} \mathrm{C}\right)$ and humidity with $12 \mathrm{~h}$ light-dark cycle along the time of the study. The animals were allowed to a standard rat pellet and water ad libitum. The research protocol was approved by the Animal Research Ethics Committee of Al-Mustansiryhia University in accordance with the globally adopted guidelines of the animal care and experiments.

\section{Experimental design and treatment}

The rats were randomly allocated into 12 groups (each of 5 rats). The groups (1, 2, and 3) were served as control and received the vehicle alone. The groups $(4,5$, and 6) were exposed to $12.5 \mathrm{mg} / \mathrm{kg}$ of AgNPs suspension intrapertonealy (i.p) for 10, 20, and 30 days, respectively. The groups (7, 8, and 9) were exposed to $25 \mathrm{mg} / \mathrm{kg}$ AgNPs i.p for 10, 20 , and 30 days, respectively. Finally, the groups $(10,11$, and 12) were exposed to $50 \mathrm{mg} / \mathrm{kg}$ of AgNPs i.p for 10, 20, and 30 days, respectively. At the end of the exposure time, the animals were anesthetized by ether and blood samples were obtained directly from the heart. The animals were dissected, and the thyroid glands were removed, weighed and kept in $10 \%$ buffered formalin for the preparation of microscopic section. The blood was left to clot and centrifuged for $10 \mathrm{~min}$ at $3000 \mathrm{rpm}$. The resulted serum was utilized for the measurement of T3, T4, and thyroidstimulating hormone (TSH) levels using ELISA technique according to standard procedures [12-14].

\section{Histological examination}

According to the procedure described by Adeyemi and Akanji [15], the thyroid tissue was fixed in $10 \%$ formalin, dehydrated with ascending grades of ethanol (70\%, 90\%, and 95\%), then cleaned in xylene and embedded in paraffin wax (melting point $56^{\circ} \mathrm{C}$ ). Tissue sections were prepared and stained with hematoxylin and eosin. The photomicrographs were captured at $\times 100$ using the software Presto ImageFolio package.

\section{Statistical analysis}

The data were presented as mean \pm SD and analyzed, using GraphPad Prism 6.1 software, with unpaired $t$-test and ANOVA. $\mathrm{p}<0.05$ was considered to be significant.

\section{RESULTS}

\section{Thyroid weight}

The exposure to a high-dose $(50 \mathrm{mg} / \mathrm{kg}$ ) of AgNPs for 20 and 30 days produced a significant $(\mathrm{p}<0.05)$ increase in the weight of thyroid gland compared with control groups, while nonsignificant changes were observed with the other doses. Moreover, short-term exposure (10 days) to any of three doses of AgNPs has no significant effect on the thyroid gland (Fig. 1)

\section{Thyroid hormones}

In the present study, the serum levels of $\mathrm{T}_{3}$ and $\mathrm{TSH}$ displayed nonsignificant changes $(\mathrm{p}>0.05)$ among all groups $(12.5,25$, and $50 \mathrm{mg} / \mathrm{kg}$ ) at different time intervals (Figs. 2 and 3). Meanwhile, a highly significant reduction $(\mathrm{p}<0.01)$ in the mean values of the $\mathrm{T} 4$ achieved after the long and intermediate duration of exposure (30 days) to $50 \mathrm{mg} / \mathrm{kg}$ of AgNPs. The exposure to $25 \mathrm{mg} / \mathrm{kg}$ showed a comparable result only after 30 -day duration compared with the control group and the other exposed groups (Fig. 4)

\section{Histological study}

In the control group, the thyroid tissue sections showed normal structure of variable sized follicles, which are filled with colloid materials. The lining epithelial cells appeared with low cuboidal morphology (Fig. 5). After 10 days of intraperitoneal injection of AgNPs doses $(12.5,25$, and $50 \mathrm{mg} / \mathrm{kg})$ did not impact the structural integrity of the thyroid tissue. Slight changes were observed when the exposure duration was extended to 20 and 30 days at low and intermediate doses. Only the groups of animals exposed to a high-dose (50 mg/kg) for 20 and 30 days showed distinct histological changes in the thyroid tissues, appeared as segregation of follicles and depletion of the colloid materials that associated with an increase in the spaces between the

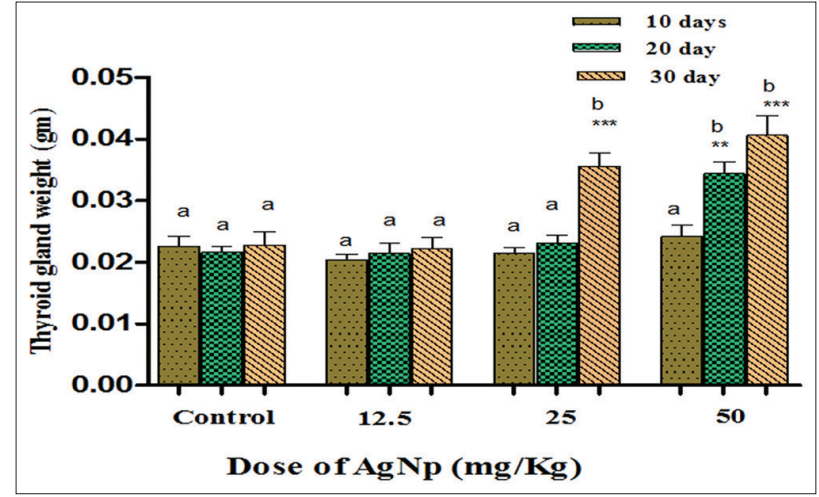

Fig. 1: Effect of different silver nanoparticles concentrations on the thyroid gland weight at different exposure periods. ${ }^{* *}$ Significantly different compared with the corresponding control group $(p<0.01) ;{ }^{* * *}$ very highly significant differences compared with the corresponding control group $(p<0.001)$ values with different letters

$(a, b)$ are significantly different among different groups $(p<0.05)$

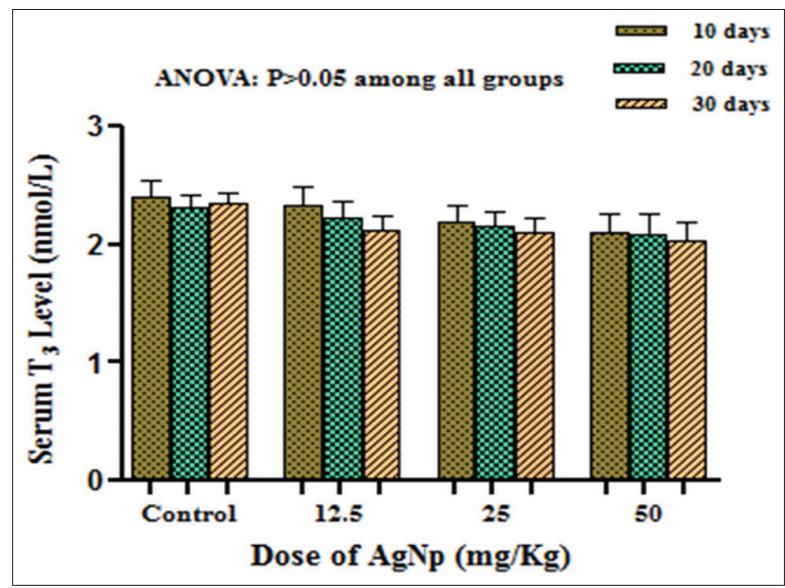

Fig. 2: Effect of rat exposure to different doses of silver nanoparticles on the serum T3 levels at different treatment duration. No significant changes were reported among the groups $(p>0.05)$

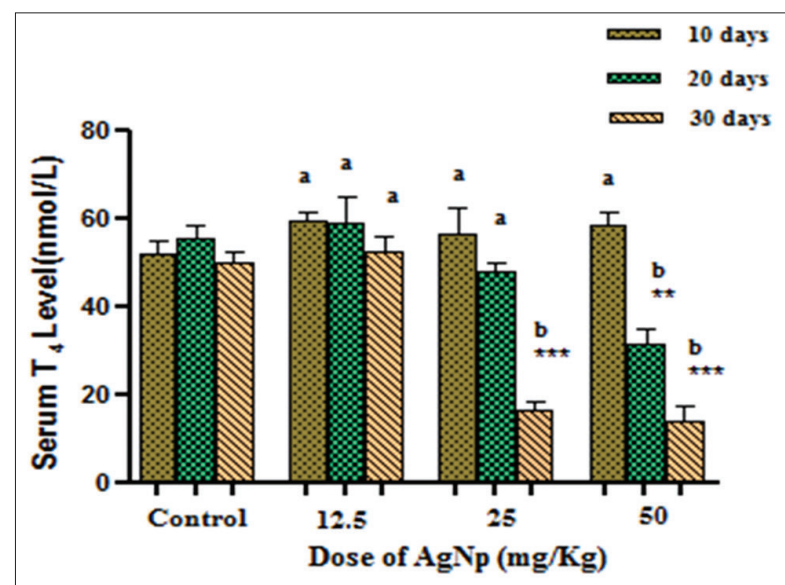

Fig. 3: Effect of rat exposure to different doses of silver nanoparticles on the serum $\mathrm{T}_{4}$ levels at different treatment duration; **significantly different compared with the corresponding control group $(p<0.01)$; ***very highly significant differences compared with the corresponding control group $(p<0.001)$; values with different letters $(a, b)$ represent the among the different groups are significantly different $(p<0.05)$

follicles (Figs. 6 and 7) compared with the control group. However, 20day exposure shows a mild effect in term of structural changes of the follicles relative to those of 30-day exposure. 


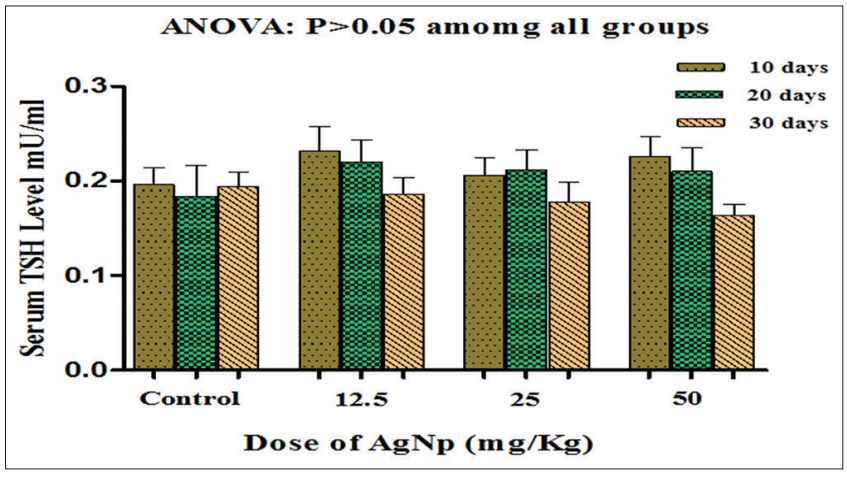

Fig. 4: Effect of rat exposure to different doses of silver nanoparticles on the serum thyroid-stimulating hormone levels at different treatment duration. No significant changes were reported among the groups $(p>0.05))$

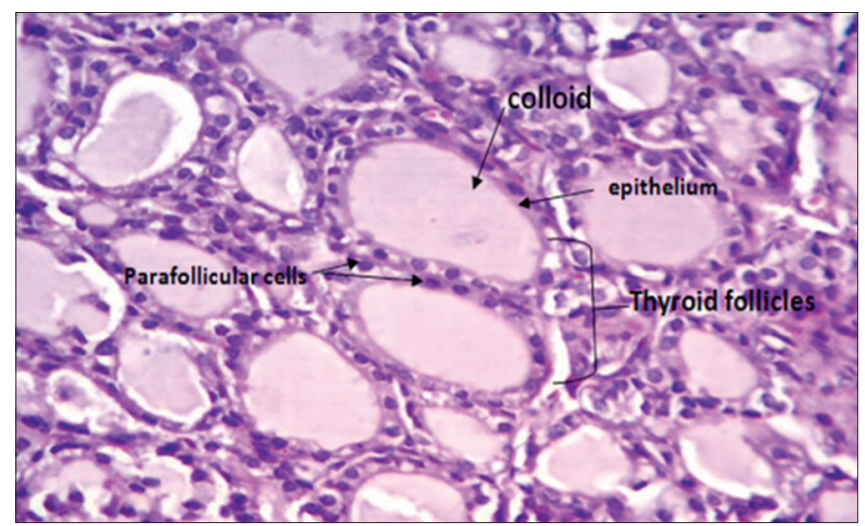

Fig. 5: Section of the thyroid gland from the control group

( $H$ and $E$ ) $\times 400$ shows the normal structure of the follicles filled with colloid material and lined by cuboidal epithelium cells

\section{DISCUSSION}

The wide applications of AgNPs in nonmedical and pharmacological products directed the search toward safety guidelines and possible toxicity mediated by the release of biologically active Ag+ into the human body [16]. In this concern, the results of the present study agreed with the data reported by Soukup et al., where they found a significant increase of thyroid gland weight in animals with hypothyroidism due to thyroid gland hypertrophy [17]. The function of the thyroid gland is often maintained by a negative feedback mechanism, which involves the interplay between the hypothalamus (through the TRH release) and the TSH released from the pituitary gland. This regulatory effect adjusts the levels of the circulating thyroid hormones (T3 and T4) [18]. These thyroid hormones played critical roles in the metabolic and developmental functions of the body. Therefore, any alteration in the levels of these hormones will negatively affect the processes of development and differentiation [19]. Many chemicals were reported to disrupt thyroid function in laboratory animals and humans [20]. Since the small particle size of NPs including AgNPs contributes to extensive tissue penetration, it can be postulated that they may disrupt the structure and function of the thyroid gland. However, no previous studies showed a reliable data in this respect [21], and this raises the need for more studies to assess the effect of exposure time and concentrations of AgNps on the thyroid function.

In the present study, assessment of the thyroid status as hyperthyroid or hypothyroid was done by measuring the serum levels of $\mathrm{T}_{3^{\prime}}, \mathrm{T}_{4}$ and TSH. Even though TSH is considered as a biomarker for hypothyroidism, many xenobiotics can modify the circulating thyroid hormones levels without considerable changes in the TSH level [22]. Our data were in tune with the

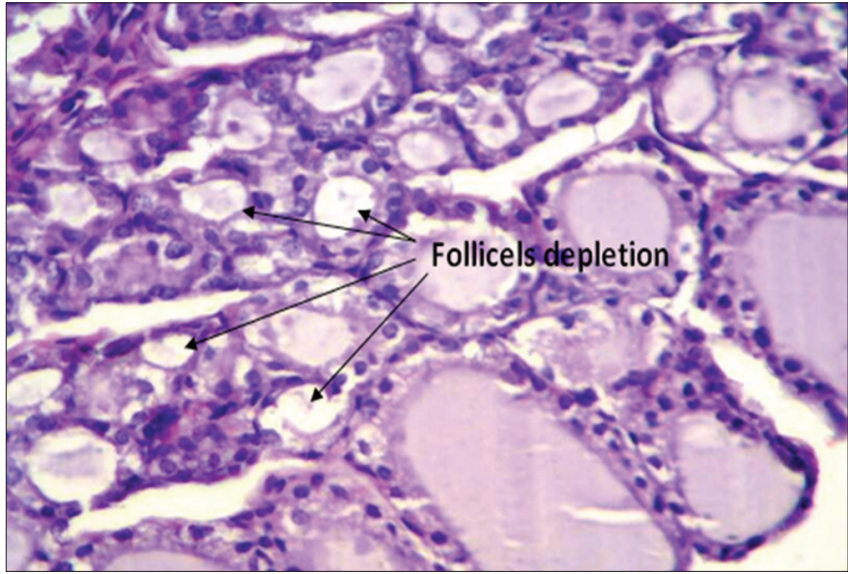

Fig. 6: Section of the thyroid gland of the rats exposed to $50 \mathrm{mg} /$ $\mathrm{kg}$ of silver nanoparticles for $\mathbf{2 0}$ days. $\mathrm{H}$ and $\mathrm{E} ; \times \mathbf{1 0 0}$ shows some of the follicles depleted of their colloidal material with slight injury of the epithelial layer of the follicles

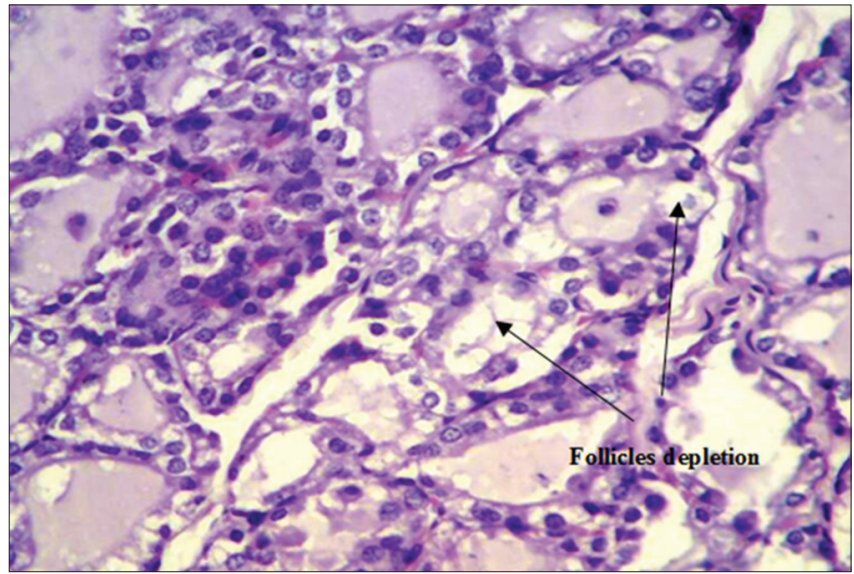

Fig. 7: Section of the thyroid gland of rats exposed to $50 \mathrm{mg} / \mathrm{kg}$ of silver nanoparticles for $\mathbf{3 0}$ days. $\mathrm{H}$ and $\mathrm{E}$; $\times \mathbf{1 0 0}$ shows more prominent depletion of the colloidal material and necrotic epithelial cells. Some of the follicular epithelial cells appeared squamous in shape

previous finding, as the present study reflects a significant reduction in the serum level of $\mathrm{T}_{4}$ with chronic exposure to increased concentrations of AgNPs, suggesting a time- and dose-dependent thyroid disrupting effect of AgNPs. However, no significant alterations ( $p>0.05$ ) were found in the levels of $\mathrm{T}_{3}$ and TSH levels (Figs. 2 and 3). Moreover, a previous study done by Hinther et al. supports the present finding, where they reported that exposure to AgNPs (5-10 nm) decreases the level of $\mathrm{T}_{4}$ by suppressing the transcript encoding thyroid hormone receptor proteins and both AgNPs and ionic Ag have the potential to perturb TH-dependent transcript abundance [23]. Other previous study reported that chronic exposure to sub lethal dose of silver nanoparticles disrupts thyroid hormone signaling, which may explain the result of this study concerning thyroid function after long term exposure (30) day, to high dose of AgNps (50 $\mathrm{mg} / \mathrm{Kg}$ ) [24]. Meanwhile, others suggested that the reduction of $\mathrm{T}_{4}$ due to the endocrine disruptor metals was attributed to the alteration in the expression of thyroid hormone synthesis gene in hypothalamic-pituitarythyroid axis [25]. In general, most of the thyroid disruptor chemicals affect the thyroid status by interfering with the different steps involved in thyroid hormone production such as iodine trapping process, cellular uptake, and interconversion between thyroid hormones, disposition, and elimination of the hormone [26]. Since many properties of AgNPs, including particle size, shape, composition and surface chemistry, may facilitate cellular penetration of these particles and can induce irreversible 
oxidative damages to both cells and organelles specially the mitochondria. Accordingly, AgNPs may alter the mitochondrial function of the thyroid epithelial cells, which might reduce cellular ATP production required as an energy source for synthesis and release of thyroid hormone[25]. Accordingly, the low level of $\mathrm{T}_{4}$ may in part resulted from the effect of AgNPs on the iodine transport system, expression of thyroid binding protein, as well as enhancing the clearance of the hormone [27]. However, the absence of the significant response of TSH release to decreased levels of $\mathrm{T}_{4}$ could be attributed to the possible interference of AgNPs with the central regulatory mechanism on the thyroid hormone production, as reported with other thyroid disruptor metals like cadmium [28]. Moreover, AgNPs may alter the mitochondrial function of the thyroid epithelial cells, which might reduce cellular ATP production required as an energy source for synthesis and release of thyroid hormone [27]. It has been reported that AgNPs induced mitochondrial dysfunction and activated the caspase- 3 that may consequently directed the cell toward mitochondrial-dependent apoptosis [29]. However, other study disagreed with our finding, where they found that daily exposure of animals to different doses $(20,50$ and $150 \mathrm{mg} / \mathrm{kg}$ ) of iron oxide NPs for 15 consecutive days resulted in a significant increase in the serum levels of T4, accompanied by significant reduction in TSH serum levels [30].This can be explained by the ability of the absorbed NPs to circulate with blood and passed to accumulate within different organs including thyroid tissue as their distribution was known to be size dependent[31-33]. Other researchers reported that the possible mechanism by which AgNPs induce thyroid toxicity is by increasing the release of reactive oxidants that induce cellular oxidation injury. They found that intraperitoneal administration AgNPs can induce oxidative injury in the hepatic and renal tissues through the inhibition of mitochondrial electron transport chain required to maintain cellular energy production[34-36]. However, the generation of reactive species may be associated with inflammatory reaction and genotoxic events [37]. Moreover, it has been found that smallest AgNPs can destruct small bio-membranes by suppression of cellular ATP level which followed by cell death $[38,39]$.

Actually, the generation of Reactive oxygen species (ROS) has both beneficial effects as defense molecules against microorganisms, as well as; they may act as signaling molecules to develop cellular stress responses which directed the cell toward death. Therefore, with time increasing levels of ROS can adversely affect the structural and functional integrity of various biological organs $[40,41]$. In this study, we have suggested that hormonal and structural alteration of the thyroid gland could be one of the consequent events to oxidative injury induced by chronic exposure to AgNPs. The results of microscopic examination of the thyroid tissue were compatible with the results of thyroid hormones results, where a considerable histological alteration in the thyroid tissue was observed after exposure to a high-dose (50 mg/ $\mathrm{kg}$ ) of AgNps during 20-30 days (Figs. 6 and 7), manifested by the depletion of follicular colloidal materials and necrotic injury of the follicular epithelial cells, which was found to be increased with longer duration.

\section{CONCLUSION}

According to the results, we can conclude that the thyroid gland was affected by chronic exposure to a high-dose of AgNps, which may be considered as an indication of AgNPs toxicity. Further studies are needed to explore such a finding.

\section{ACKNOWLEDGMENT}

The authors would like to thank the Department of Biology, College of Science, Mustansiriyah University, Baghdad, Iraq, for supporting the project.

\section{AUTHORS' CONTRIBUTION}

All authors contribute equally in the collection of data and performing data analysis of the present study. In addition, the paper was written by the corresponding author.

\section{CONFLICTS OF INTEREST}

None declared.

\section{REFERENCES}

1. Kumar P, Roy I. Applications of gold nanoparticles in clinical medicine. Int J Pharm Pharm Sci 2016;8:9-16.

2. Furtado LM, Bundschuh M, Metcalfe CD. Monitoring the fate and transformation of silver nanoparticles in natural waters. Bull Environ Contam Toxicol 2016;20:20.

3. Kahru A, Dubourguier HC. From ecotoxicology to nanoecotoxicology. Toxicology 2010;269:105-19.

4. Garcia T, Lafuente D, Sanchez DJ, Sirvent JJ, Domingo JL, Gomez M. Oral subchronic exposure to silver nanoparticles in rats. Food Chem Toxicol 2016;92:177-87.

5. Singh M, Manikandan S, Kumaraguru AK. Nanoparticles: A new technology with wide applications. Res J Nanosci Nanotechnol 2010;10:1996-2014

6. Jassim AM, Al-Kazaz FF, Kamel LA, Farhan SA, Noori OM. Biochemical study for gold and silver nanoparticles on thyroid hormone levels in sera of patients with chronic renal failure. J Pharm Chem Biol Sci 2015;3:91-103

7. Lavado-Autric R, Ausó E, García-Velasco JV, Arufe Mdel C, Escobar del Rey F, Berbel P, et al. Early maternal hypothyroxinemia alters histogenesis and cerebral cortex cytoarchitecture of the progeny. J Clin Invest 2003;111:1073-82.

8. Ausó E, Lavado-Autric R, Cuevas E, Del Rey FE, Morreale De Escobar G, Berbel P, et al. A moderate and transient deficiency of maternal thyroid function at the beginning of fetal neocorticogenesis alters neuronal migration. Endocrinology 2004;145:4037-47.

9. Shirband A, Azizian H, Pourentezari M, Rezvani ME, Anvari M, Esmaeilidehaj M. Dose-dependent effects of iron oxide nanoparticles on thyroid hormone concentrations in liver enzymes: Possible tissue destruction. Global J Med Res Stud 2014;1:28-31.

10. Ribeiro MJ, Maria VL, Scott-Fordsmand JJ, Amorim MJ. Oxidative stress mechanisms caused by Ag nanoparticles (NM300K) are different from those of agNO3: Effects in the soil invertebrate Enchytraeus crypticus. Int J Environ Res Public Health 2015;12:9589-602.

11. Khanna P, Ong C, Bay BH, Baeg GH. Nanotoxicity: An interplay of oxidative stress, inflammation and cell death. Nanomaterials (Basel) 2015;5:1163-80.

12. Gharib H, Mayberry WE, Ryan I, Hockert T. Radioimmunoassay for triiodothyronine (T3): Affinity and specificity of the antibody for T3. J Endocrinol 1971;33:509.

13. Barker SB. Determination of protein bound iodine. J Biol Chem 1948; 173:715-24.

14. Fisher DA. Physiological variations in thyroid hormones: Physiological and pathophysiological considerations. Clin Chem 1996;42:135-9.

15. Adeyemi OS, Akanji MA. Psidium guajava leaf extract: Effects on rat serum homeostasis and tissue morphology. Comp Clin Pathol 2010;21:401-7

16. Elkhawass EA, Mohallal MA, Soliman MF. Acute toxicity of different sizes of silver nanoparticles intraperitoneally injected in BALB/C mice using two toxicological methods. Int J Pharm Pharm Sci 2014;7:94-9.

17. Soukup T, Zacharová G, Smerdu V, Jirmanová I. Body, heart, thyroid gland and skeletal muscle weight changes in rats with altered thyroid status. Physiol Res 2001;50:619-26.

18. Zoeller TR. Environmental chemicals targeting thyroid. Hormones (Athens) 2010;9:28-40

19. Berbel P, Mestre JL, Santamaría A, Palazón I, Franco A, Graells M, et al. Delayed neurobehavioral development in children born to pregnant women with mild hypothyroxinemia during the first month of gestation: The importance of early iodine supplementation. Thyroid 2009; $19: 511-9$

20. DeVito M, Biegel L, Brouwer A, Brown S, Brucker-Davis F, Cheek AO, et al. Screening methods for thyroid hormone disruptors. Environ Health Perspect 1999;107:407-15.

21. Boas M, Feldt-Rasmussen U, Main KM. Thyroid effects of endocrine disrupting chemicals. Mol Cell Endocrinol 2012;355:240-8.

22. Miller MD, Crofton KM, Rice DC, Zoeller RT. Thyroid-disrupting chemicals: Interpreting upstream biomarkers of adverse outcomes. Environ Health Perspect 2009;117:1033-41

23. Hinther A, Vawda S, Skirrow RC, Veldhoen N, Collins P, Cullen JT, et al. Nanometals induce stress and alter thyroid hormone action in Amphibia at or below north American water quality guidelines. Environ 
Sci Technol 2010;44:8314-21.

24. Carew AC, Hoque ME, Metcalfe CD, Peyrot C, Wilkinson KJ, Helbing $\mathrm{CC}$, et al. Chronic sublethal exposure to silver nanoparticles disrupts thyroid hormone signaling during xenopus laevis metamorphosis. Aquat Toxicol 2015;159:99-108.

25. Miao W, Zhu B, Xiao X, Li Y, Dirbaba NB, Zhou B, et al. Effects of titanium dioxide nanoparticles on lead bioconcentration and toxicity on thyroid endocrine system and neuronal development in zebrafish larvae. Aquat Toxicol 2015;161:117-26.

26. Boas M, Feldt-Rasmussen U, Main KM. Thyroid effects of endocrine disrupting chemicals. Mol Cell Endocrinol 2012;355:240-8.

27. AshaRani PV, Low Kah Mun G, Hande MP, Valiyaveettil S. Cytotoxicity and genotoxicity of silver nanoparticles in human cells. ACS Nano 2009;3:279-90.

28. Kelly GS. Peripheral metabolism of thyroid hormones: A review. Altern Med Rev 2000;5:306-33.

29. Pavia B, Hagmuller K, Noli MI, Hagmuller K, Zaninovich AA. Evidence suggesting that cadmium induces a non thyroidal illness syndrome in rat. J Endocrinol 1997;154:113-7.

30. Shirband A, Najafi L, Babadi VY, Beigi-Zarji ME, Najafi A, Mirzakhani F, et al. Effect of iron oxide nanoparticles on thyroid hormones in rats. Appl Chem 2013;56A:13883-5.

31. Kim YS, Song MY, Park JD, Song KS, Ryu HR, Chung YH, et al. Subchronic oral toxicity of silver nanoparticles. Part Fibre Toxicol 2010;7:20

32. Austin CA, Umbreit TH, Brown KM, Barber DS, Dair BJ, FranckeCarroll S, et al. Distribution of silver nanoparticles in pregnant mice and developing embryos. Nanotoxicology 2012;6:912-22.
33. Hillyer JF, Albrecht RM. Gastrointestinal persorption and tissue distribution of differently sized colloidal gold nanoparticles. J Pharm Sci 2001;90:1927-36.

34. Costa CS, Ronconi JV, Daufenbach JF, Gonçalves CL, Rezin GT, Streck EL, et al. In vitro effects of silver nanoparticles on the mitochondrial respiratory chain. Mol Cell Biochem 2010;342:51-6.

35. Hussain SM, Hess KL, Gearhart JM, Geiss KT, Schlager JJ. In vitro toxicity of nanoparticles in BRL 3A rat liver cells. Toxicol In Vitro 2005;19:975-83.

36. Asharani PV, Hande MP, Valiyaveettil S. Anti-proliferative activity of silver nanoparticles. BMC Cell Biol 2009;10:65.

37. Sarhan OM, Hussein RM. Effects of intraperitoneally injected silver nanoparticles on histological structures and blood parameters in the albino rat. Int J Nanomedicine 2014;9:1505-17.

38. Umbreit TH, Francke-Carroll S, Weaver JL, Miller TJ, Goering PL, Sadrieh $\mathrm{N}$, et al. Tissue distribution and histopathological effects of titanium dioxide nanoparticles after intravenous or subcutaneous injection in mice. J Appl Toxicol 2012;32:350-7.

39. Gopinath P, Gogoi SK, Sanpui P, Paul A, Chattopadhyay A, Ghosh SS, et al. Signaling gene cascade in silver nanoparticle induced apoptosis. Colloids Surf B Biointerfaces 2010;77:240-5.

40. Salman RA. The effect of different doses levels of silver nanoparticles (AgNPs) on the kidney and liver in albino male rat. Histopathol Study 2014;11:1503-9.

41. Hassanin KM, Abd El-Kawi SH, Hashem KS. The prospective protective effect of selenium nanoparticles against chromium-induced oxidative and cellular damage in rat thyroid. Int $\mathrm{J}$ Nanomedicine $2013 ; 8: 1713-20$ 